Document downloaded from:

http://hdl.handle.net/10251/97806

This paper must be cited as:

Riera-Guasp, M.; J. Antonino-Daviu; Capolino, G. (2015). Advances in Electrical Machine, Power Electronic, and Drive Condition Monitoring and Fault Detection: State of the Art. IEEE Transactions on Industrial Electronics. 62(3):1746-1759. doi:10.1109/TIE.2014.2375853

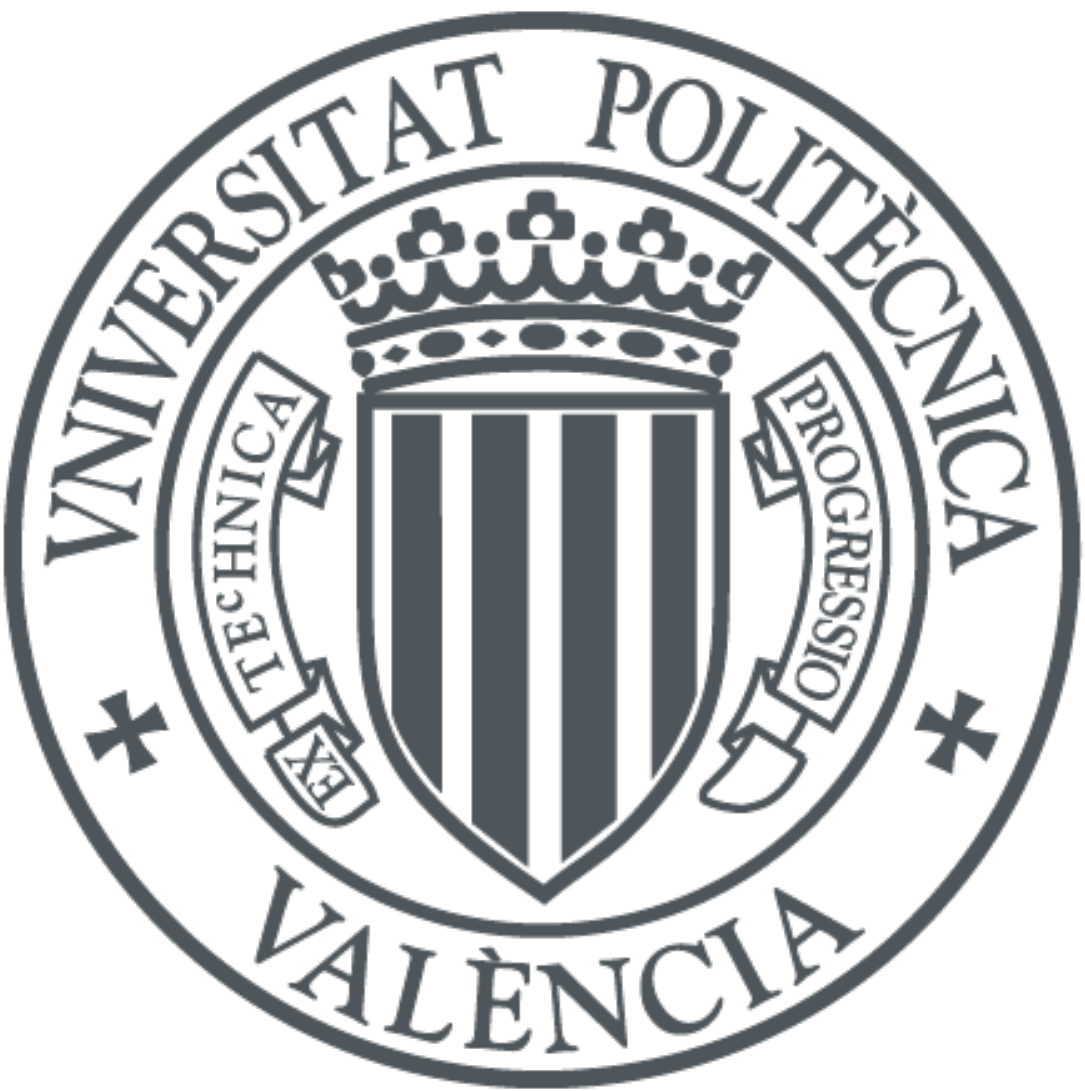

The final publication is available at

http://doi.org/10.1109/TIE.2014.2375853

Copyright Institute of Electrical and Electronics Engineers

Additional Information 


\title{
Advances in Electrical Machine, Power Electronic and Drive Condition Monitoring and Fault Detection: State of the Art
}

\author{
Martin Riera-Guasp, Senior Member, IEEE, Jose A. Antonino-Daviu, Senior Member, IEEE, and \\ Gérard-André Capolino, Fellow, IEEE
}

\begin{abstract}
Recently, research concerning electrical machines and drives condition monitoring and fault diagnosis has experienced extraordinarily dynamic activity. The increasing importance of these energy conversion devices and their widespread use in uncountable applications have motivated significant research efforts. This paper presents an analysis of the state of the art in this field. The analyzed contributions were published in most relevant journals and magazines or presented in either specific conferences in the area or more broadly scoped events.
\end{abstract}

Index Terms-- Bearing faults; Condition monitoring; Fault diagnosis; Induction machines; Insulated gate bipolar transistors; Mechanical faults; Partial discharge; Permanent magnet synchronous machines; Power converters; Rotor asymmetries; Stator faults; Stray flux; Transient analysis

\section{INTRODUCTION}

$\mathrm{O}$ VER recent years, the research activity in the electrical machines and drives predictive maintenance area has experienced spectacular dynamism. This has been partially due to the incorporation of these elements in a vast number of industrial processes and applications. Moreover, these elements are often critical in those processes in which they operate. Large motors and generators, whose eventual failures may lead to severe repercussions in economic terms (repair costs, production shutdowns) as well as other less tangible costs (customer delivery delays, user hazard, efficiency reduction) are especially key issues for industry. All of these factors have justified increasing efforts to develop new techniques able to detect the development of any faults sufficiently in advance that proper maintenance actions can be planned and adopted.

Traditionally, squirrel-cage induction machines (IMs) have attracted the most attention in electric machine fault diagnosis (FD) research due to their widespread usage. Recently, other types of rotating electrical machines, such as permanent magnet synchronous machines (PMSM), wound rotor induction machines (WRIM), multiphase AC machines (nPIM or nPPMSM with $n$ being the number of phases and larger than 3) and switched reluctance machines (SRM), are increasingly being used. This is due to either the emergence of new applications (wind power generation, electric vehicles, cranes, elevators, high-speed trains, etc.) or the necessity of guaranteeing operation even under the presence of a fault (fault-tolerant systems). Consequently, the

Manuscript received August 14, 2014; revised November 8, 2014; accepted November 18, 2014

Copyright (C) 2014 IEEE. Personal use of this material is permitted.

However, permission to use this material for any other purposes must be obtained from the IEEE by sending a request to pubs-permissions@ieee.org

M. Riera-Guasp and J. A. Antonino-Daviu are with the Instituto de Ingeniería Energética, Universitat Politècnica de Valencia, 46071 Valencia, Spain (e-mail: mriera@die.upv.es; joanda@die.upv.es).

G. A. Capolino is with the Laboratory of Innovative Technologies (EA3899), University of Picardie "Jules Verne," 80000 Amiens, France (e-mail: Gerard.Capolino@ieee.org). importance of new research lines in the aforementioned area, quickly increasing.

This notable dynamism of the electric machine FD research community is proven by a number of unquestionable indicators concerning the increasing number of recent papers in the area. Moreover, these topics have contributed to the success of relevant conferences.

Although there are excellent recent review papers in this area [1], [2], the aforementioned dynamic activity has led to the appearance of very new contributions of indubitable interest. These facts have encouraged authors of this paper to develop a state-of-the-art presentation that intends to synthesize the most recent advances in electric machine, drive and power electronic FD. More specifically, authors would like to comment on contributions published in relevant publications.

Considering the large number of contributions dealing with IM FD, the paper has been structured so that a detailed analysis of contributions concerning these machines will be given in Section II. IM faults have been classified into three main groups: rotor faults, stator winding failures and mechanical faults (eccentricities, bearing faults, gear box damage). The subsequent sections will directly address the recent research advances in the FD of other machines and drives: Section III will focus on PMSMs, while Section IV will address FD in power electronic converters and power electronics components. Despite being classified in the field of power electrical engineering, this paper will not address the power system fault detection in a global way (e.g., lines, cables, insulators, and breakers).

\section{INDUCTION MACHINES FAULT DIAGNOSIS \\ A. Fault Diagnosis of Rotors}

Rotor faults are usually linked to the appearance of asymmetries in either the rotor cage in squirrel-cage machines (broken bars or end rings, rotor core damage) or the rotor windings in wound-rotor machines (different winding impedances). These faults can be due to a variety of reasons, as summarized in [1]: thermal and electromagnetic stresses, electromagnetic noise and vibrations, environmental or mechanical stresses, part fatigue, damaged bearings, centrifugal forces or connection defects. A thorough review specifically focused on IM rotor FD can be found in [3]. This work explains the physical basis of rotor faults, summarizes the most relevant classical papers and comments on recent works, pointing out emerging trends in this field.

1) Digital signal analysis techniques applied to rotor Fault Diagnosis

A comprehensive review devoted to digital signal analysis techniques applied to IM FD can be found in [4]. This paper proposes a classification criterion based on the domain in which the extracted features are defined: the frequency 
domain, the time-frequency-time-scale domain and the time domain

Frequency-domain techniques basically rely on the detection of characteristic fault-related frequencies in the Fourier spectrum of the tested signal. As stated in [3], they are well suited for steady-state operation and rated modes of operation, although some drawbacks arise when these techniques are applied in industrial environments. Low-load, fluctuating-load and time-varying conditions as well as special magnetic structures [3] or combined faults can invalidate basic frequency-domain techniques. Recent works dealing with these issues can be found in [5]-[6].

The problem of diagnosing rotor asymmetries at very low load conditions is overviewed in [5], where the authors proposed the Teager-Kaiser energy operator as a demodulation technique. The FD in the frequency domain, when working conditions are not strictly stationary, requires the use of short sampling periods. In these cases, techniques based on spectral estimation as ESPRIT [6] can be useful because they have the advantage of detecting frequencies from short data with high resolution in specific frequency intervals. Nevertheless, subspace methods as ESPRIT or MUSIC have a computation complexity of $O\left(N^{3}\right)$ which makes their application to real time systems unsuitable [4]. A recent trend relies on the development of new techniques with low computational requirements that can be implemented in the digital controller of electronic converters or in low-cost electronic devices, as the Teager-Kaiser energy operator (TKO) [5]. In this work, TKO is used for demodulating a current signal instead the Hilbert transform, reducing the computational cost from $O(N \cdot \log N)$ to $O(N)$. Nevertheless, all of these methods assume that the tested signal is stationary and lead to unsatisfactory results when applied to electrical machines working under non-stationary conditions. For such cases, time-frequency-domain- and time-domain-based techniques are considered more suitable than frequency-domain approaches. Under non-stationary conditions, the fault-related frequencies used by the conventional machine current signature analysis (MCSA) or other steady-state frequency-domain techniques lead to components with variable magnitudes and frequencies. Using suitable time-frequency transforms, these fault-related components can be tracked in the time-frequency plane [7]. A Wigner Ville distribution (WVD)-based approach has been introduced in [8], where the authors proposed preprocessing the analyzed signal using improved finite impulse response (FIR) notch filters, which are able to remove frequencies not related to faults (winding space harmonics, supply frequencies and saturation harmonics) and efficiently attenuate cross-terms without affecting the resolution of the time-frequency energy density representation.

In [9], an optimized linear transform is introduced. This technique, called adaptive transform (AT), has been designed to overcome some drawbacks of the well-known short-time Fourier transform (STFT) and continuous wavelet transform (CWT). The AT, uses a function called the timefrequency atom at each point of the $\mathrm{t}-\mathrm{f}$ plane. This function has been optimized for extracting the energy of the searched fault component on that point.

The Hilbert-Huang transform (HTT) is another technique recently used for tracking fault frequency components in a faulty machine working in non-stationary conditions [10]. In this paper, the lower sideband frequency component associated with bar breakage is extracted during a startup

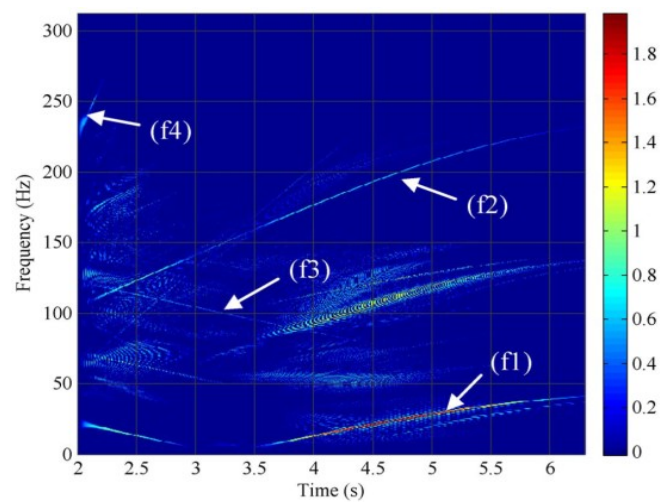

(a)

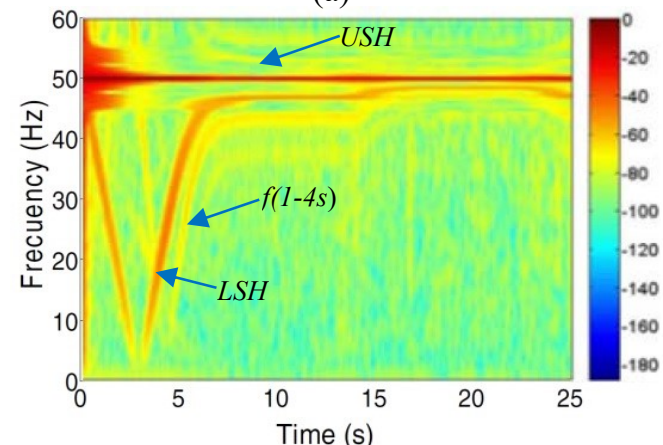

(b)

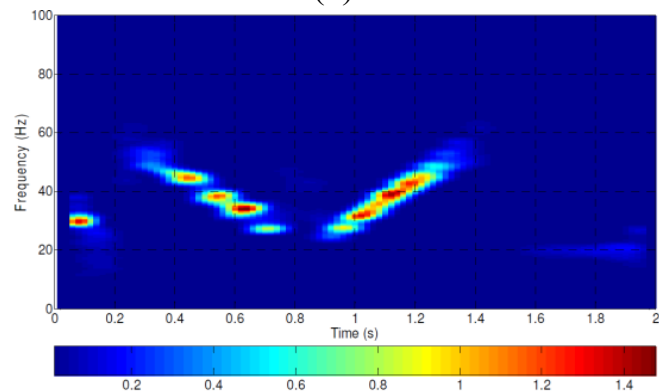

(c)

Fig.1 FD of one broken bar during startup by using different time-frequency approaches: a) Wigner-Ville distribution [8] - b) Optimized adaptive transform [7] - c) Hilbert-Huang transform [10].

using the empirical mode decomposition (EMD) and the Hilbert spectrum.

Fig. 1 shows the results supplied by three aforementioned time-frequency techniques: Wigner-Ville distribution [8], optimized adaptive transform [7]; Fig.1(c) Hilbert-Huang transform [10].

Table I summarizes some relevant characteristics of these approaches, enabling for a qualitative comparison. All these transforms are considered to have high computational complexity, not suitable for real time applications or low cost devices implementation.

A challenging problem for FD under non-stationary conditions is the case of electrical machines submitted to

TABLE I

QUALITATIVE COMPARISON OF RELEVANT CHARACTERISTICS OF REFERENCED TIME-FREQUENCY APPROACHES

\begin{tabular}{|c|c|c|c|}
\hline t-f Approach & $\begin{array}{c}\text { Wigner-Ville + } \\
\text { Notch Filter [8]. }\end{array}$ & $\begin{array}{c}\text { Adaptive Trans- } \\
\text { form [7], [9] }\end{array}$ & $\begin{array}{c}\text { Hilbert-Huang } \\
\text { Transform [10] }\end{array}$ \\
\hline Figure & 1 (a) & $1(\mathrm{~b})$ & $1(\mathrm{c})$ \\
\hline Theoretical basis & $\begin{array}{c}\text { Quadratic } \\
\text { Tansform }\end{array}$ & Linear Transform & $\begin{array}{c}\text { Empirical Adaptive } \\
\text { Transform }\end{array}$ \\
\hline Resolution & High & High & Low \\
\hline $\begin{array}{c}\text { Tracking multiple } \\
\text { components }\end{array}$ & $\begin{array}{c}\text { Yes: (f3), } f(5-4 s) \\
(f 2)\end{array}$ & $\begin{array}{c}\text { Yes: LSH, USH, } \\
\text { f(1-4s) }\end{array}$ & No (only LSH) \\
\hline $\begin{array}{c}\text { Working conditions } \\
\text { Industrial } \\
\text { application }\end{array}$ & Startup & $\begin{array}{c}\text { Startup + Steady } \\
\text { State (low slip) }\end{array}$ & Startup \\
\hline \multicolumn{2}{|c|}{} & Feasible & $\begin{array}{c}\text { More research } \\
\text { needed }\end{array}$ \\
\hline
\end{tabular}


continuous and random changes in load or supply conditions [7]. In these cases, the magnitudes and frequencies of fault components also change randomly, and there are no predefined patterns in the time domain that enable the characterization of these faults. Recent works, such as [11], [12], have dealt with this problem, and the techniques developed therein have been applied to FD in wound-rotor induction generators (WRIG) used in wind power generation. Basically, both mentioned works share the same conceptual principle, which consists in detecting increases in the signal energy into specific frequency bands, which should contain the fault components when the fault arises. Up to now, the DWT has been used as a filtering tool, for isolating the frequency interval of interest. Nevertheless, the DWT has some inherent limitations for selecting the limits of the bands. Therefore, the use of other more accurate types of filters should be investigated for enhancing the results with this kind of approaches.

Advanced signal analysis techniques, as those commented in these sections, seem to be good candidates for improving the diagnostic systems in the wind power generation industry. However, they have been rarely incorporated in commercial systems. This is probably due to a lack of coordination between the signal requirements of these techniques and the limitation imposed by the data transmission systems used by the centralized condition monitoring (CM) scheme, commonly used in wind generation. Research efforts should be made for fixing this issue, in such a way that these powerful tools can be incorporated to the predictive maintenance scheme of the wind farms.

\section{2) Design of new AI-based algorithms for automatic} rotor fault detection, classification and prognosis.

The application of advanced tools has led to the proliferation of new algorithms for automatic fault detection and classification that rely on features obtained with the aforementioned tools. Some of these classification algorithms are based on classical artificial intelligence (AI) tools that have been adapted to advances in the signalprocessing area. In this regard, the application of neural network (NN)-based methods to IM rotor fault is far from new. Some recent works have reactivated the use of this AI tool, taking advantage of either novel and optimized network topologies or the combination of advanced signal-processing tools (for feature extraction) and $\mathrm{NN}$ (for classification). Additionally, some recent contributions combine the use of statistical data and neural networks for fault detection and classification. More specifically, [13] proposes a method based on the combination of a feature-extraction technique that relies on the smoothed ambiguity plane designed for maximizing the separability between classes using Fisher's discriminant ratio and a feature-selection technique based on an error probability model to select an optimal number of extracted features. The proposed scheme provides good results regarding the FD of not only broken bars but also stator or bearings. Reference [14] uses the statistical features of time-domain data as well as spectral data as a basis for the construction of a $\mathrm{NN}$ for rotor fault detection and classification.

Something similar can be said about support-vector machine (SVM)-based approaches, which have received renewed attention over recent years. Reference [15] provides good examples of recent applications of SVM-based methods to classify rotor damage faults.
In [16], the potential successful extrapolation of nonconventional techniques that are well-known in other scientific areas to the IM FD field has been described. The authors propose an unsupervised classification technique known as artificial ant clustering to detect and classify rotor and bearing failures in IMs at different load levels.

Other authors make use of widely used methods in the image-processing and pattern-recognition fields for the automatic detection of rotor failures. For instance, [17] employs the intelligent icons approach for the automatic assessment of the rotor condition based on the analysis of the startup current. The principal component analysis in combination with kernel density estimation is proposed in [18] to identify the stator current state space patterns of a healthy motor and a motor with different faults (broken bars, eccentricities and connection defects), achieving highly accurate classification results.

\section{3) Use of alternative quantities to detect rotor damage.}

The benefits of using other quantities for FD purposes have been investigated in another set of works. The search for non-invasive approaches enabling the reliable FD of certain failures that are not easily detectable with currents or vibrations has been a common challenge for many authors.

In this context, [19] confirms the possibilities and potential provided by the analysis of the stray flux for fault detection purposes, considering two types of faults: broken bars and inter-turn short-circuits. The authors develop an analytical model of the external magnetic field and the faulty machine. Their study concludes that the magnetic field in the vicinity of the machine contains very useful information related to its health and that, using such simple models, it is possible to determine the relative variation of spectral lines without needing the magnitude itself.

In [20], the authors have used FEM to study the influence of the rotor slot number on the amplitude of the broken bar fault signature. The authors analyze different quantities, including line current, torque, apparent power and zerosequence current, and conclude that, in their opinion, this latter quantity is the best for broken-bar FD purposes because it is less affected by the rotor slot number and offers the strongest fault signature for every studied rotor slot number case.

4) Development of new theoretical models and studies that facilitate the analysis of the fault start and development and its effects.

The development of theoretical studies and specific models to enhance the understanding of different aspects of rotor FD has been the motivation of a number of recent works.

In this regard, [21] presents a simple but effective analytical representation of IM with rotor faults that is based on a synchronous reference frame and on Steinmetz's phasors. It facilitates the understanding of the physical phenomenon behind the failure and improves the fault severity quantification of the usual MCSA technique, based on the sum of the current sideband amplitudes, by employing the active and reactive components of the current ripple as well as phasors.

The physics of the rotor fault generation process as well as the effects of this process on different indicators are studied in [22]. The authors develop a fatigue test designed to induce rotor bar breakage in a natural way. They develop fatigue models based on their results and evaluate the performance 
of current-based indicators based on both steady-state and transient analysis.

Reference [23] is an interesting and unconventional work that, rather on focusing on fault conditions, analyzes the stator current spectrum of IM with healthy rotors. Their study helps to clarify and characterize the components that should appear in the current spectrum under healthy conditions, considering MMF space harmonics, slot permeance harmonics and the saturation of the main magnetic flux path through the virtual air-gap permeance variation. Their work facilitates the further identification of faulty cage-related components when a fault is present in the machine.

The machine's parameter variation under progressive levels of rotor failure is studied in [24]. The authors change the alignment of rotor with respect to the stator magnetic axis and obtain the dependence of the machine parameters on rotor angle. The advantage of this approach is that they can analyze different combinations of broken bars without needing actual motor samples.

Interesting studies on the effect of the rotor failure on other electromechanical quantities are presented in several works. [25] studies the influence of the broken bar fault on the harmonic content of the magnetic flux density and on the electromagnetic torque spectrum, concluding that the study of this latter spectrum is useful at frequencies near $300 \mathrm{~Hz}$. On the other hand, [26] performs an interesting analysis of how different air-gap waves, such as flux density and mechanical stresses, are affected by the cage fault by presenting a two-dimensional spectral analysis based on both quantities.

\section{B. $\quad$ Stator Winding Insulation Condition Monitoring and Fault Diagnosis}

The winding insulation is one of the systems of electrical machines that is most prone to faults. Faults related to winding insulation comprise between $21 \%$ and $40 \%$ of total failures in electrical machines [27], [28] depending on the type and size of the machine. A comprehensive review of $\mathrm{CM}$ and fault detection regarding winding insulation can be found in [28], [29].

Winding faults are usually the final result of the slow and continuous aging of the windings insulation. An aged winding can locally fail due to a small stress (brief overheating, vibration, transient overvoltage) generating an inter-turn short circuit fault, after which a fault current circulates through the damaged turns. The thermal effect of the fault current progressively degrades the insulation of the affected and neighboring turns. The fault progressively spreads, and the fault current increases. Finally, the slot insulation or insulation of another phase can be affected, leading to a catastrophic phase-ground or phase-phase failure. This process develops rather quickly [29]. If appropriate measures are not taken within a few seconds, the localized failure can evolve to catastrophic failure [28]. As indicated in [29], the issue of winding failures must be tackled differently, depending on the importance and size of the machine.

\section{1) Insulation System Condition Monitoring.}

This technique is used for important, large, high-voltage machines. For such machines, knowledge of the insulation condition is crucial because it allows optimizing their exploitation. The aim of these methods is the CM of the degree of aging of the insulations. CM of winding insulation can be performed in two different ways [29]:

- Using periodical off-line standard tests (measurements of insulation resistance, Hipot tests, power factor tests, turnto-turn insulation tests, partial discharges tests).

-Through continuous CM of different quantities, such as the winding temperature, chemical composition of gases and vibrations or even partial discharge on-line CM. Such approaches are expensive and are only used in critical machines. An example of on-line partial discharge $\mathrm{CM}$ is described in [30], where indications of the insulation system degradation of a low-voltage induction motor fed by a frequency converter are obtained in agreement with the IEC 60034-18-41 Standard.

Moreover, in this area, research efforts are also dedicated to develop models for forecasting the remaining lifespan of the machine insulation [27], [31]. Reference [27] presents a method for modeling the lifespan of insulation materials based on the design of experiments. In [31], this model is improved using statistical tools, such as response surface and analysis of variance.

\section{2) Insulation Fault Diagnosis}

These techniques are commonly used in low-voltage machines. The winding insulation diagnostic approaches do not provide information about the degree of insulation aging [29]; rather, their objective is limited to detecting inter-turn short-circuit faults in their early stages, enabling suitable actions to prevent these faults from degenerating into catastrophic faults. Thus, to be of practical interest, inter-turn short-circuit FD methods must be able to detect the fault very quickly, in its early stages, when the fault current remains low or at least before the conventional protection systems (overcurrent or differential relays) act. There are different techniques for inter-turn short-circuit FD:

-Inter-turn short-circuit Fault Diagnosis via MCSA

In induction machines, inter-turn short-circuits generate harmonic components in the stator phase current. Their characteristic frequencies have been extensively analyzed in the literature [28]. Many techniques based on the traditional MCSA approach or other more recent methods based on modern signal analysis methodologies have been proposed. In [4], a comprehensive review is performed on recently developed digital signal-processing tools that are applied to the stator current of induction machines for the detection of electrical and mechanical faults.

On the other hand, many of the MCSA techniques are based on the comparison of the spectrum of the diagnosed machine with a spectrum of the same machine in a healthy state. To facilitate the application of such methods, the aforementioned reference [23] develops a comprehensive characterization and classification of the harmonics components present in the spectrum of the stator current of a healthy cage rotor machine.

Another physical phenomenon that enables the FD of interturn short-circuits is the appearance of a negative-sequence component in the supply currents [29]. The faulty phase has fewer turns than the healthy phases and thus generates less electromotive force and has different impedance, leading to an unbalanced system of three-phase currents. Examples of recent FD methodologies based on the inverse-sequence component can be found in [32], [33].

In [32], the authors deduce analytical expressions for the symmetrical components of the stator phase current under 
different stator winding faults (inter-turn short-circuit, phaseto-phase and phase-to-ground faults). From these expressions, the authors suggest the use of the magnitude and phase of the inverse and zero-sequence components of the phase current as stator faults indicators. Reference [33] proposes an approach to detecting and locating a stator turnto-turn fault in a multiple-motor drive system based on the change in the transfer impedance $\Delta Z_{n p}$ from the positivesequence currents to the negative-sequence voltage of the motors. In laboratory tests, the authors experimentally show that it is possible to detect a one-turn stator fault in a closedloop multiple-motor drive with 432 turns per phase.

Nevertheless, these methods share a common drawback: other causes not related to short-circuit faults can also introduce a negative-sequence component in the current, such as unbalanced supply voltages, constructive asymmetries and non-tuned current sensors. It should be noted that this drawback is important because it reduces the sensitivity to incipient faults, which is crucial in short-circuit fault detection. Recently, several investigations have attempted to overcome this problem, as in [34], where the authors introduce a technique for the compensation of negative-sequence current components that are not related to stator faults, including in this case the effect of voltage unbalance.

One issue that is rarely addressed is the need for a rapid response to prevent catastrophic damage when an inter-turn short-circuit fault arises. If the conventional FFT is used to detect faulted components in an early stage, a high frequency resolution is required. But this leads to long sampling periods, which could be longer than the time required to develop a catastrophic failure. Fig. 2 [33] illustrates a tradeoff between resolution and fast response; the authors of that work use a sampling time of $0.25 \mathrm{~s}$ (five periods of the sampled signal for a supply frequency of $20 \mathrm{~Hz}$ ), which leads to a frequency resolution of $4 \mathrm{~Hz}$, for calculating the spectrum of the complex current vector, in order to detect the negative and positive sequence currents $\left(I_{n}, I_{p}\right)$. Effective approaches need to use signal processing techniques for reaching suitable frequency resolution with short sampling periods. At the same time, they should not have heavy computational requirements, so that that processing almost in real time is feasible. As an example, [33] uses the Goertzel algorithm for calculating the bins of interest for FD, almost in real time. Anyway, this issue needs further research in the field of Inter-turn short-circuit by MCSA methods.

Another relevant issue is whether or not such reaction times are short enough for avoiding catastrophic consequences. Regarding this concern, more studies on the evolution of the short-circuit fault in actual applications would be necessary, for helping to establish criteria on suitable reaction times for the diagnosing this kind of faults.

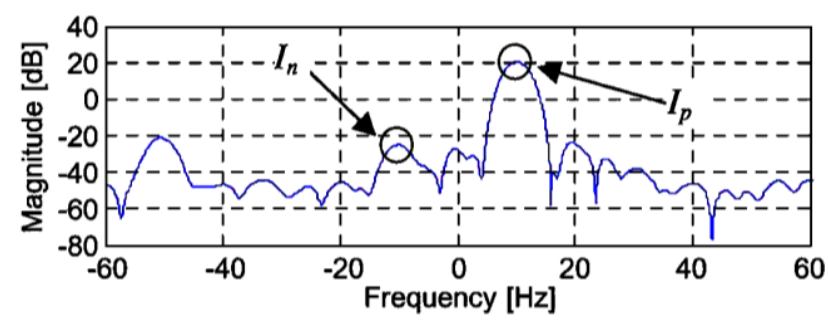

Fig.2 Trade-off between resolution and fast response requirements, for detecting negative sequence component in the current vector (frequency resolution $4 \mathrm{~Hz}$, sampling period $0.25 \mathrm{~s}$ ) [33].
-Inter-turn short-circuit Fault Diagnosis via analysis of stray flux

FD methods relying on current measurement are widely used because they are non-invasive and avoid the use of specific sensors. Nevertheless, as stated [29], other magnitudes, such as stray flux [19], [35], [36], have specific advantages that make them attractive for certain applications.

The FD of windings based on measurements of stray flux has recently attracted considerable interest [19]. FD methods relying on the stray flux are completely non-invasive and easy to set up. On the other hand, they require specific sensors, and the distribution of the magnetic flux around the machine may be difficult to know and depends strongly on the constructive characteristics of the machine frame [1].

In [35], the FD via the stray flux is based on the use of two probes placed in specific positions near the machine frame. The analysis relies on comparing the variation with the load of the amplitude of a specific harmonic in both probes. The authors state that a relevant feature of this method is that it does not require knowledge of the machine behavior in the healthy state. Reference [19] introduces a simplified analytical model that allows the approximate determination of the external magnetic flux under healthy and faulty conditions for the cases of stator inter-turn short-circuit and rotor broken bars.

Other short-circuit FD methods based on measurement of the stray flux can be found in [36], where the authors use different flux probes placed at different positions around the machine. The FD is based on the analysis of the harmonics multiple of the main frequency through statistical evaluation.

Compared with the MCSA method, a drawback of FD through stray flux is that the results depend on the location of probes, and is not possible to specify a general rule for the optimal location, since it is directly related to the frame constructive characteristics. On the other hand, the possibility to change the position of probes brings the opportunity of developing methods for an accurate location of the fault.

\section{-Artificial intelligence approaches for short-circuit Fault Diagnosis}

AI techniques can be used to classify the state of the machine into a series of pre-defined classes, including healthy state, different types of faulty states and different fault severity degrees, without the use of complex algorithms and to support decision-making procedures [1]. A review of the application of AI techniques to the FD of inter-turn faults can be found in [28]; after evaluating several significant contributions in these fields, the authors conclude that artificial models, once trained, provide a fast and accurate simulation of the machine. However, these models are machine-specific and require extensive training to provide good results under all conditions. In recent works, artificial neural networks (ANN) are applied to the FD of inter-turn short-circuits in induction machines in different applications. In [37], an ANN approach is applied to a wound-rotor induction generator. The authors apply a classical ANN with back-propagation, but it is trained directly by digital signals coming from sensors, leading to a diagnostic system with a simplified architecture that could be set up using low-cost hardware, such as field-programmable gate arrays (FPGAs). In [38], an ANN approach is applied to a squirrel cage induction motor fed through an inverter. In this work, a fault progression indicator $\xi_{\mathrm{x}}$ is used as input of the ANN. This 
TABLE II

TECHNIQUES For CM AND FD OF IMS STATOR WINDINGS

\begin{tabular}{|c|c|c|c|c|}
\hline & Purpose & Techniques & Industrial penetration & Remarks \\
\hline \multirow[b]{2}{*}{$\begin{array}{l}\text { Insulation } \\
\text { system } \\
\text { CM }\end{array}$} & \multirow{2}{*}{$\begin{array}{l}\text { Knowing } \\
\text { aging } \\
\text { degree and } \\
\text { remaining } \\
\text { life of } \\
\text { windings }\end{array}$} & $\begin{array}{l}\text { Periodical of-line test: } \\
\text { Insulation Resistance, } \\
\text { Hipot test, Partial } \\
\text { Discharges [29] }\end{array}$ & $\begin{array}{l}\text { Done, standard } \\
\text { methods }\end{array}$ & \multirow[b]{2}{*}{$\begin{array}{l}\text { High-power, High-Voltage, } \\
\text { critical Machines }\end{array}$} \\
\hline & & $\begin{array}{l}\text { Continuous monitoring } \\
\text { of: Windings } \\
\text { temperature, Gases } \\
\text { composition, vibrations, } \\
\text { Partial Discharges [29], } \\
{[30]}\end{array}$ & Done, special cases & \\
\hline \multirow{3}{*}{$\begin{array}{l}\text { Insulation } \\
\text { Fault } \\
\text { detection } \\
\& \\
\text { diagnosis }\end{array}$} & \multirow{3}{*}{$\begin{array}{l}\text { Fast } \\
\text { Detection of } \\
\text { inter-turn } \\
\text { short- } \\
\text { circuits }\end{array}$} & $\begin{array}{l}\text { MCSA: Spectral analysis, } \\
\text { negative sequence } \\
\text { component analysis [4], } \\
{[23],[32],[33],[34],[35]}\end{array}$ & Low, feasible & $\begin{array}{l}\text { Need of fast algorithms for } \\
\text { calculation of spectral } \\
\text { components, Results affected } \\
\text { by Influence of external } \\
\text { phenomena on negative } \\
\text { sequence current }\end{array}$ \\
\hline & & $\begin{array}{l}\text { Stray Flux Analysis [19], } \\
\text { [36], [37] }\end{array}$ & $\begin{array}{l}\text { Low, More research } \\
\text { needed }\end{array}$ & $\begin{array}{l}\text { Results depending of probes } \\
\text { location and frame } \\
\text { constructive characteristics }\end{array}$ \\
\hline & & \begin{tabular}{|l|} 
Artificial Intelligence \\
Approaches[1], [28],[38]
\end{tabular} & Low, Feasible & $\begin{array}{l}\text { Extensive trained needed, } \\
\text { machine specific }\end{array}$ \\
\hline
\end{tabular}

indicator relies on the variation of the phase-shift between the phase voltages and line currents in the healthy and faulty machine.

Of course, the aforementioned limitations of reaction time are also applicable to stray flux analysis and AI techniques for diagnosing inter-turns short-circuits. Table II summarizes the main features of the techniques for $\mathrm{CM}$ and $\mathrm{FD}$ of stator windings in IMs.

\section{Fault Diagnosis of Mechanical Failures}

\section{1) Fault Diagnosis of rotor eccentricities.}

A certain level of eccentricity is normal in every machine. The manufacturing tolerances of the rotor and stator or inaccuracies during the machine assembly process, among other factors, may lead to non-uniform air-gap lengths. These asymmetries are usually amplified during the machine operation due to the degradation of some of the machine elements (bearing wear, rotor damage...), misalignments with the driven load, gear box deterioration, etc. Increasing eccentricity values may lead to unbalanced magnetic pull, vibrations, shaft currents (which can damage the bearings), frame and winding loosening, insulation fretting and even stator-rotor rubs [1]. The goal is to determine the eccentricity threshold for serious problems with the machine. Researchers have yet to reach an agreement on such a value.

A significant strand of research has been carried out over years to determine the eccentricity levels in IM by either developing new techniques or exploiting the potential of the existing ones.

The use of the line stator current as a basis of these methods is a common point for many of the developed works. Some works deepen in the analysis and optimization of the traditional MCSA method, such as [39], which presents a new fault severity index based on the amplitudes of current components at $f \pm f_{r}$ and considers the interaction between static- and dynamic-eccentricity flux density waves. Some other works have extended the eccentricity FD to machines operating under non-stationary regimes. For example, in [40], the instantaneous frequency analysis of fault components in the stator current is employed to detect eccentricities in wound-rotor IM operating under fluctuating loads.

Several recent contributions have explored the viability of other quantities for FD purposes. Reference [41] proposes the use of the terminal voltage spectra at switch-off for detecting moderate levels of static as well as dynamic eccentricities. The proposed approach works well for any machine, overcoming the constraints of traditional highfrequency-component-based methods that only work well for certain pole pair and rotor slot combinations. Reference [42] presents a method based on axial flux analysis that makes use of an external coil sensor. Their analysis is oriented towards the detection of the low-frequency components of the FFT spectrum (such as $s \cdot f$ and $3 \cdot s \cdot f$ ). The use of the zerosequence current spectrum is proposed in [43] to detect static eccentricities in delta connected IM.

Finally, the development of new models that facilitate the study of the machine under eccentricity fault has also been the motivation of a number of recent works, such as [44], in which a mono-harmonic model able to reproduce all types of eccentricities is proposed.

Despite the number of recent works in the topic, there are still some unsolved issues, as the avoidance of the load influence as well as the difficult discrimination between static and dynamic eccentricities [1]. Some attempts have intended to overcome some of these issues [41], but there is still a predominance of FD techniques relying on indicators based on the detection of the overall level of mixed eccentricity.

\section{2) Bearings Fault Diagnosis}

Depending on the type and size of the machine, bearing faults account for approximately $40 \%$ (large machines) to $90 \%$ (small machines) of faults [45]. Although the use of vibration signals or even noise is widespread, their need for specific sensors and the frequently difficult discrimination between faults have stimulated research in FD methods based on other quantities [1].

The stator current has been proposed as an interesting alternative, and some studies have furthered the current vs. vibration comparison for the detection of such faults [45]. In this context, [1] reports some difficulties with diagnosing bearing faults when using current analysis, such as the influence of supply unbalances or variable speed drives (VSDs) on the bearing fault signs. Indeed, this latter issue has been the motivation of a number of recent works that have focused on the influence of converters on the bearing damage. For instance, [46] studies the effects of bearing currents on different quantities of converter-driven IMs. In [47], the same group of authors develops a complete study that demonstrates that it is possible to calculate in advance the bearing currents in inverted-fed IM to estimate the lifetime of the bearings.

Despite the problems with current-based bearing assessment, [1] recommends the convenience of using the available current or voltage sensors to diagnose such failures. Several works have followed this suggestion and developed interesting current-based techniques for the FD of different types of bearing damage. Reference [48] proposes a method that combines the entropy analysis of wavelet signals and neural networks for bearing fault detection and classification.

Other authors have suggested the use of other quantities to diagnose bearing problems in IM. Reference [49] suggests the statistical processing of stray flux data to diagnose three different types of bearing failures. The results reveal the greater significance of the analysis based on quantity in comparison with the analysis of stator current.

Despite these advances in the use of currents and other quantities for bearing $\mathrm{FD}$, the use of vibration-based techniques is still more common. Some works have focused on their optimization or even the automation of the bearing 
fault detection process, such as [50]. Reference [51] also proposes an approach based on SVM to automatically detect and classify bearing problems, relying on noise reduction to facilitate the detection of vibration components. Reference [52] combines the envelope analysis of vibration signals, the sliding fast Fourier transform (FFT) technique and principal component analysis (PCA) to diagnose bearing faults. The main advantage of this method is that it overcomes the usual prior estimation of the characteristic bearing fault frequencies. Finally, [53] presents an interesting approach to plastic bearing FD based on a two-stage process that combines envelope analysis and EMD to pre-process vibration signals and extract fault-related features. In spite of the wide variety of algorithms relying on different models and signal processing techniques, no clear general choices have emerged [1].

The prognosis of bearing faults has also been a common topic in several recent works [1]. Reference [54] presents an interesting study of the bearing and gear fault generation processes, describing various recent methods for their identification. The aforementioned work places special emphasis on the research trends in the bearing and gear fault prognosis areas. The convenience of using more than one sensor, the suitability of both data-driven and model-based techniques and the use of hybrid techniques to follow the trend of a fault are noted by the author. Reference [55] employs vibration signals to predict the degradation of bearings using a time-series forecasting model called the neo-fuzzy neuron. The development of physics-based models is also a common topic, such as in [56], which develops a model to detect bearing damage capable of predicting fault development.

Despite the indubitable advances in bearing damage FD and prognosis based on different quantities, there are still some open questions in the topic. In this regard, the search for techniques relying on quantities that can be directly measured in the drive terminals rather than on the bearings is a goal that has not been solved yet (especially, taking into consideration the problems of current-analysis for diagnosing bearing damages). Also, the development of techniques that are able to discriminate faults with similar signatures and suitable to be implemented in low-cost CM systems is an open concern for many researchers in the field [1].

\section{3) Fault Diagnosis of damage in gear boxes.}

Within the IM FD field, gear box faults have also attracted significant attention recently. Reference [54] notes two possible fault modalities that are rather common in gears: 1) gears wear uniformly, resulting in backlash, and 2) one or more teeth wear out due to impact or a manufacturing fault, which can result in impact during teeth meshing and further degradation.

As some studies have recently reported [57], vibrational and acoustic analyses seem to be the most appropriate approaches to detecting gear tooth wear faults, whereas current analysis is more problematic because the faultrelated harmonics amplitudes are near the noise level and it is necessary to use long data acquisition and high-resolution systems to detect some of these amplitudes properly. Table III shows a qualitative comparison of the FD capabilities of these three quantities when detecting pinion tooth wear fault in gear boxes, based on the conclusions of [57]. Nevertheless, special techniques relying on the instantaneous
TABLE III

QUALITATIVE COMPARISON BETWEEN FD CAPABILITIES OF VIBRATION, ACOUSTIC PRES- SURE AND CURRENTS WHEN DETECTING PINION TOOTH WEAR FAULT IN GEAR BOXES [57]

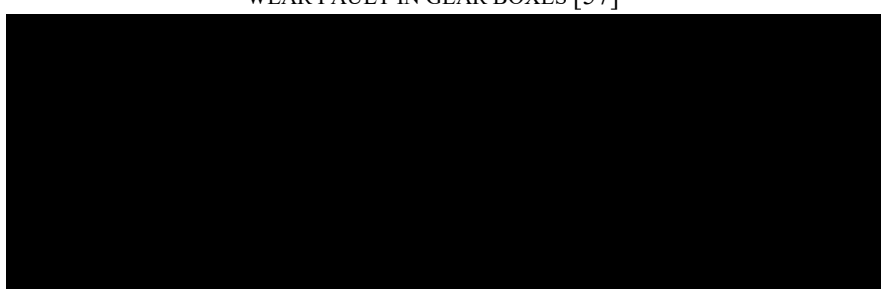

frequency of the stator current space vector have provided good results [58-59] due to the integer-multiple harmonics of the rotation frequency that appear due to the fault.

More specifically, [59] proposes the reconstruction of the fault profile from the measured torque and the instantaneous frequency (IF) of the stator current space vector and subsequent computation of the fault profile energy. Fig. 3 clearly shows the great differences between fault profiles from the IF of the stator current space vector at rated load for different faulty conditions related to the pinion $(\mathrm{P})$, the wheel (W), the simultaneous synchronous pinion-wheel (SSPW) and the simultaneous asynchronous pinion-wheel (SAPW) tooth surface damage faults, respectively. The work proves that, in terms of energy, the IF of the stator current space vector provides comparable fault sensitivity with the measured torque for the different faulty conditions.

The virtues of acoustic analysis in detecting gear faults are ratified in [60], where an acoustic-emission-based intelligent wireless sensor combined with the use of neural networks is presented.

Other recent studies have focused on gear FD in a variety of applications, such as cement kiln drives [61], railway traction systems [62] and wind generation systems [63].

\section{Research on Multiphase Induction Machine}

The increasing interest in multiphase AC machines has led to the merging of the research activity on multiphase machines and multiphase drives. As [64] notes, this interest has been partially due to the greater number of degrees of freedom of these machines relative to three-phase machines.

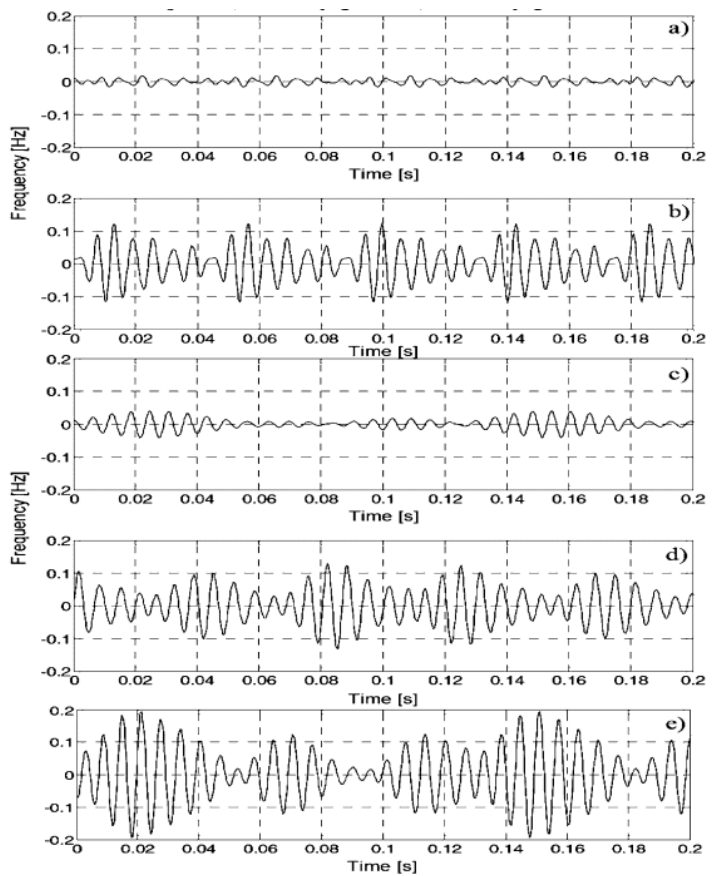

Fig. 3. Reconstruction of fault profile from the instantaneous frequency of stator current space vector at rated-load: a) Healthy gear - b) P-faulty gear c) W-faulty gear - d) SSPW-faulty gear -e) SAPW-faulty gear [59]. 
This feature allows some of the spatial harmonics of the airgap magnetic field to be controlled independently of each other. In this context, [64] and [65] investigate the behavior of multiphase IM with an odd number of phases under the assumption that the resistances of the stator winding are unbalanced due to poor connections. The authors present an interesting control strategy that can detect the stator resistance unbalance and localize the faulty phase while keeping the drive behavior unchanged in both transient and steady-state operating conditions.

\section{Permanent Magnet Synchronous Machines Fault DIAGNOSIS}

PMSMs have proliferated over recent years thanks to the development of rare-earth magnetic materials, such as Sm$\mathrm{Co}$ and Nd-Fe-B. These new permanent magnets can improve the specific power, performance and power factor of PMSM relative to equivalent induction motors [66]. Wind generation, electrical vehicles and robotics are some of the fields in which PMSMs are being massively used today. Consequently, the interest in CM and FD techniques for these machines is rapidly increasing in industry and academia. The main faults in PMSMs include electromagnetic faults, such as demagnetization of the rotor permanent magnets and stator-winding short circuits, and mechanical faults, such as rotor eccentricities and bearing damage [66].

\section{A. Demagnetization Fault Diagnosis}

When a local defect arises in a magnet, specific harmonics appear in the spatial distribution of the magnetic flux density [67]. In this work, the authors conclude that the subsequent variation of the harmonic content in the back-EMF can be suitable for local demagnetization FD despite the strong dependence of the harmonic content on the stator winding configuration. In contrast, for uniform demagnetization, no new harmonics appear in the spectrum of the back-EMF, and these authors propose the detection of the variations of the amplitude related to the fundamental of already existing harmonics as a FD approach.

Local demagnetization is also analyzed in [68]. In this work, the authors demonstrate that this fault generates characteristic fractional harmonics in the back-EMF of a single coil, although these harmonics can disappear in the phase back-EMF depending on the windings configuration. To avoid this drawback, the authors propose to monitor the zero-sequence voltage component (ZSVC). Simulations and tests show that the local demagnetization fault leads to reductions in the amplitude of the ZSVC that may enable the fault detection, although this approach requires that windings have an accessible neutral and also, an artificial neutral point, which is set up using a three-phase balanced resistor network connected to the machine terminals. Fig.4 [68] compares the ZSVC measured in a six poles PMSM in

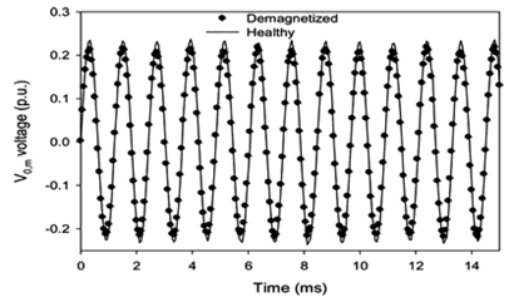

Fig.4 Experimental ZSVC voltage of a healthy and a partially demagnetized SPMSM operating at $6000 \mathrm{rpm}$ [68]. healthy state and under partially demagnetized condition rotating at $6000 \mathrm{rpm}$. Obviously, approaches proposed in [67], [68] require accurate information of the behavior of the machine in healthy condition. In [69], the authors propose a finite element model which takes into account the motor shaft displacement due to the unbalanced magnetic forces that partial demagnetization produces. This improved model gives a more realistic simulation of the currents than conventional FEM models. Nevertheless, the main drawback of this model is that it requires the knowledge of the shaft displacement evolution, which in this work the authors experimentally measure using an innovative laser sensor. One of the goals of this work is demonstrate the importance of the mechanical effects in the partial demagnetization fault. The demagnetization FD under non-stationary conditions is presented in [66]; the aim of this method is to extract the optimal features for FD from the transient current signals. This is performed in a pre-processing stage based on the application of the Choi-Williams distribution followed by fractal dimension calculations based on the computation of the box-counting method.

\section{B. $\quad$ Stator Winding Short-Circuits}

Stator short-circuit faults are an especially important problem for permanent-magnet (PM) machines because they can produce magnetic field intensities higher than the coercivity of the magnets, thereby demagnetizing the magnets permanently and, in the process, damaging the machine [28]. Reference [70] introduces a FD approach based on comparing a real-time-estimated back electromotive force (EMF) with a reference EMF. In this work, the EMF estimator is based on a stator current tracking scheme, and covers the thermal and saturation phenomena. The reference EMF has to be previously computed by either FE analysis or real measurements at a known speed for the healthy machine and is stored in a lookup table. This process of building the lookup table has to be performed for each machine before starting their actual use, and may be a drawback in real applications; counterpart, once tuned, the system is able to react instantly against inter-turn shortcircuits.

A fault indicator for on-line inter-turn short-circuits based on an extended Kalman filter approach is introduced in [71]. The aim of this work is to develop a detection approach with very fast response capability. The authors report that the proposed fault indicator enables the reliable detection of a fault involving $4 \%$ of the turns of a phase. Importantly, it reacts quickly, on the timescale of an electrical cycle.

Special machines used in some relevant applications, as the claw-pole generators used in conventional vehicles, require specific FD methods; a method for stator turn FD in claw-pole generators is proposed in [72]. Given the difficulty in accessing the physical quantities usually monitored, the authors propose testing the DC output voltage and current and show that, in the rectified generator output current, the harmonic at one-third of the rectifier ripple frequency is a robust signature of the stator turn fault.

\section{Mechanical Fault Diagnosis}

The diagnoses of eccentricities and localized bearing damage have been traditionally carried out through frequency-domain approaches applied to current and vibration signals. Nevertheless, these techniques fail when the characteristic frequencies change due to the variations of the rotating speed. To overcome this problem, [73] proposes 
the demodulation of the frequency of the current signal using a phase-locked loop (PLL) algorithm and an amplitude demodulation based on a square law algorithm. After demodulation, a 1P-invariant PSD algorithm is used to discover the excitations at the variable bearing fault characteristic frequency.

\section{Research on Multiphase Permanent Magnet Synchronous Machine}

The use of multiphase PM machines is an emerging technology especially suited for applications where high reliability is needed, such as in aerospace, naval, transportation or offshore wind generation applications. In multiphase machines, when faults occur in one or more phases, the machine can maintain its operation using the remaining healthy phases, without additional hardware and with reasonable performance [74].

Significant studies on multiphase PMSM are being conducted based on the detection of different type of faults [75] as well as fault-tolerant control strategies for optimizing the machine performance after a fault arises [74].

\section{FAUlt Diagnosis In POWER COMPONENTS AND CONVERTERS}

Although power electronic drives are widespread and are used in a variety of applications, they are prone to several failures [76]. As [77] notes, the two components that are most likely to fail in switch-mode drives are electrolytic filtering capacitors and power semiconductors. Among the latter, the most typical power semiconductor faults are short circuit-and open-circuit faults.

Although most of the works in the power converter FD area address ac-dc or ac-ac converters, an increasing number of recent papers are focused on FD in $\mathrm{dc}-\mathrm{dc}$ converters [78].

\section{A. Fault Diagnosis in Power Converters}

A detailed review of the recent literature on inverter FD is developed in [79]. Reference [80] notes the characteristics of each of the two main types of switch failures in inverters: while short-circuit fault are typically very destructive and require the adoption of actions to shut down the drive immediately, open-circuit faults do not necessarily lead to system shutdown and can remain undetected for a long time (however, such faults can lead to secondary faults in other converter components that can eventually lead to high repair costs) [80].

A variety of different techniques have been applied to detect open-circuit faults in power converters. In this regard, the use of the Park vector approach is quite extensive. [1] compares the key features of different common algorithms, some of which are based on the Park vector approach: 1) a technique reported in [81] based on the use of the modulus of the Park vector to normalize phase currents (known as 'errors of normalized currents average absolute values' (ENCAAV)), 2) a method presented in [82] that relies on the value of the absolute Park vector phase derivative (called the current Park vector phase and current polarity (CPVPCP)), 3 ) the normalized current average values [83] and 4) the normalized reference current errors (NRCEs) [80]. As [1] shows, the experimental results obtained from the integration of the four methods into a digital controller of a PMSM drive reveal that each method possesses a unique robustness, detection speed, computational burden implementation effort and tuning effort. More specifically, Table IV shows that all
TABLE IV

KEY FEATURES EVALUATION OF POWER CONVERTER FD METHODS BASED ON PARK'S VECTOR APPROACH, PROVIDED IN [1]

\begin{tabular}{|l|c|c|c|c|}
\hline & ENCAAV & CPVPCP & NCAV & NRCE \\
\hline $\begin{array}{l}\text { Localization capabilities } \\
\text { (fault signatures) }\end{array}$ & 15 & 27 & 27 & 27 \\
\hline Effectiveness & High & High & High & High \\
\hline $\begin{array}{l}\text { Robustness } \\
\text { (robustness factor) }\end{array}$ & 0.76 & 1.00 & 0.23 & 0.94 \\
\hline $\begin{array}{l}\text { Detection speed (average) } \\
\text { (\% currents period) }\end{array}$ & 39.6 & 71.2 & 58.3 & 28.7 \\
\hline $\begin{array}{l}\text { Implementation effort } \\
\text { (file size in kB) }\end{array}$ & 64.9 & 73.1 & 74.7 & 63.4 \\
\hline $\begin{array}{l}\text { Computational burden } \\
\text { (execution time in } \boldsymbol{\mu s} \text { ) }\end{array}$ & 3.40 & 4.25 & 4.89 & 3.37 \\
\hline $\begin{array}{l}\text { Tuning effort } \\
\text { (parameters number) }\end{array}$ & 2 & 4 & 3 & 3 \\
\hline $\begin{array}{l}\text { Most important feature } \\
\text { concerning industrial } \\
\text { application }\end{array}$ & $\begin{array}{c}\text { Low } \\
\text { burden }\end{array}$ & $\begin{array}{l}\text { Robustness } \\
\text { against false } \\
\text { alarms }\end{array}$ & $\begin{array}{c}\text { Low } \\
\text { computational } \\
\text { burden }\end{array}$ & $\begin{array}{c}\text { Fast } \\
\text { detection }\end{array}$ \\
\hline
\end{tabular}

methods have very high FD effectiveness even for low load levels. The CPVPCP method has a particular robustness against false alarms as a consequence of load and speed transients. On the other hand, the NRCE method enables the fastest detection, while NRCE and ENCAAV methods have the lowest computational burden. Finally, the ENCAAV method involves the lowest tuning effort [1]. Other contributions have employed various alternatives to the aforementioned open-circuit failures in PE drives. The absolute value of the modulated error voltages is used in [84] for open-circuit FD in matrix converters, whereas a modelbased perspective is presented in [85] to isolate open-switch faults in IM drives. The developed scheme allows the isolation of single and simultaneous faults in power semiconductors with a fast response. Reference [86] presents a sensorless method based on monitoring the voltage vector time presence in specific sectors of the complex stationary plane. Reference [87] considers the study of open-circuit faults in power inverters and proposes techniques that rely on principal component analysis, while [88] proposes the use of SVM-based approaches.

The study of DC-link capacitors has been the motivation of a number of works. Employed as energy buffers between the utility grid and the load, electrolytic capacitors are often critical elements in power converter systems. Reference [89] performs an interesting synthesis of eventual faults in this element and develops a FD system for capacitors operating in ac/dc PWM converters. Reference [90] analyzes the performance of an inverter fed induction motor under a open-circuit de link capacitor.

Regarding dc-dc converters, the use of Kalman filters for the model-based FD of a dc-dc boost converter is proposed in [91], while [92] presents an approach based on the harmonic components of the magnetic near-field of a dc-dc converter.

In spite of the increasing number of research works aiming to enhance the reliability of power converters, there is an important concern in the industry regarding the robustness of these devices. An interesting industrial survey is carried out in [76] to determine the requirements and expectations of reliability in PE converters. The conclusions reveal that power semiconductor devices are the most fragile components. The study also highlighted the significant need in industry for better CM methods and indicators (the study points out that the satisfaction with $\mathrm{CM}$ methods is low $(50 \%)$ and the knowledge of indicators for reliability is even 
lower $(23 \%))$. The authors of the present paper agree with [76] that further research effort into the power electronic health management area (such as FD, prognosis, and CM) and more effective transfer to the industrial sector is needed.

\section{B. Power Component Fault Diagnosis}

Several recent works have addressed the FD of different faults in power electronics components. In this regard, the FD of IGBTs is studied in [77], [93]. In [93], the authors propose a new on-board CM of the aging of solder layers in IGBTs for electric vehicle applications, while [77] proposes an online PCA-based algorithm for early fault detection in IGBT switches. The fault detection and degradation of other components, such as MOSFETs, is studied in [94].

Despite there is a number of papers describing and analyzing the physics of the failure in power components as MOSFETs or IGBTs, there is still a lack of works proposing the use of the device features (e.g. on-state resistance, threshold voltage...) for on-line switch CM. This deficiency is partially due to the difficulty in obtaining the required signals that are often small and susceptible to corruption from noise [77].

\section{Fault-tolerant Drives}

The study and development of fault-tolerant systems that guarantee the continuation of the operation despite the occurrence of a fault has been pursued in many recent works within the PE drive area. This line of research has joined with the proliferation of multi-phase AC machines, which, combined with multi-phase inverters, are an interesting option for high-power applications [64].

In this context, the study of the fault-tolerant capabilities of multilevel converters has become the motivation of a number of works. For instance, in [95], IM fed by multilevel converters with fault-tolerant control strategies are considered in terms of their efficiency and thermal behavior. Additionally, multilevel topologies with FD and faulttolerant capabilities but applied to power factor correction have also been proposed in [96]. Hybrid modulation strategies for asymmetrical cascaded multilevel converters (ACMCs) operating under fault conditions in low-voltage high-frequency (LVHF) cells have also been proposed [97].

More specifically, matrix converters have also been considered by several authors, such as in [98], where faulttolerant matrix converter motor drive systems that implement a high-speed fault detection strategy for detecting and identifying faulty open-circuited switches are developed.

The advances in the area of fault-tolerant power electronics drives are being notorious and are proven by the wide variety of modified redundant topologies for multilevel converters, matrix converters and conventional three-phase bridge inverters. Nonetheless, the increase in redundancy that these new topologies imply often increments the complexity, cost of systems and even decrease some performances. It is still necessary a more effective component-level redundant design for PE systems, as some studies have pointed out [99].

\section{CONCLUSIONS}

Electrical machine and drive CM and FD has become a notably dynamic research field, with new machine and converter configurations and applications, new digital signal analysis tools, hardware devices and industrial challenges continuously appearing. Although excellent review works targeting specific fields have been published, it is difficult to obtain an overview of the most recent contributions published in both journals and conferences. A large set of significant papers published in the last three years in the area of FD and CM of electrical machines, power electronics and drives has been analyzed to help readers identify trends in the different areas of this field. Applications of advanced signal analysis techniques to FD, PMSM applications, faulttolerant drives with multiphase converters and multiphase machines have been introduced since their emergence in the last 5 years, and they will surely be developed further in the near future.

\section{REFERENCES}

[1] H. Henao, G.-A. Capolino, M. Fernández-Cabanas, F. Filippetti, C. Bruzzese, E. Strangas, R. Pusca, J. Estima, M. Riera-Guasp, and S.H. $\mathrm{Kia}$, "Trends in Fault Diagnosis for Electrical Machines," IEEE Ind. Electron. Magazine, June 2014, pp. 31-42.

[2] A. Bellini, F. Filippetti, C. Tassoni, and G.-A. Capolino, "Advances in diagnostic techniques for induction machines," IEEE Trans. Ind. Electron., vol. 55, no. 12, pp. 4109-4126, 2008

[3] F.Filippetti, A. Bellini, G.-A.Capolino, "Condition Monitoring and Diagnosis of Rotor Faults in Induction Machines: State of Art and Future Perspectives"," in Proc. IEEE Workshop Electrical Machines Design, Control and Diagnosis (WEMDCD'2013), Paris, France March 11-12, 2013, pp. 194-207.

[4] S. H. Kia, H. Henao, and G.-A. Capolino, "Efficient digital signal processing techniques for induction machine fault diagnosis," in Proc. IEEE Workshop Electrical Machines Design, Control and Diagnosis (WEMDCD'2013), Paris, France, March 11-12, 2013, pp. 230-244.

[5] M. Pineda-Sanchez, J. Perez-Cruz, J. Roger-Folch, M. Riera-Guasp, A. Sapena-Baño, and R.Puche-Panadero, "Diagnosis of Induction Motor Faults using a DSP and Advanced Demodulation Techniques," in Proc. IEEE Int. Symp. Diagnostics for Electrical Machines, Power Electronics and Drives (SDEMPED'2013), Valencia, Spain, Aug. 2730, 2013, pp. 69-76.

[6] B. Xu, L. Sun, L. Xu, G. Xu, "Improvement of the Hilbert Method via ESPRIT for Detecting Rotor Fault in Induction Motors at Low Slip," IEEE Trans. Energy Conv., Vol. 28, No. 1, pp. 225-233, March 2013.

[7] M.Riera-Guasp, J. Pons-Llinares, V. Climente-Alarcon, F. VedreñoSantos, M. Pineda-Sanchez, J. A. Antonino-Daviu, M. PuchePanadero, J. Perez-Cruz, and J. Roger-Folch, "Diagnosis of induction machines under non-stationary conditions: Concepts and tools," in Proc. IEEE Workshop Electrical Machines Design, Control and Diagnosis (WEMDCD'2013), Paris, France, Mar. 11-12, 2013, pp. 218-229.

[8] V.Climente-Alarcon, J.A. Antonino-Daviu, M. Riera-Guasp, and M. Vlcek, "Induction Motor Diagnosis by Advanced Notch FIR Filters and the Wigner-Ville Distribution", IEEE Trans. Ind. Electron., vol. 61, no. 8, pp.4217-4227, August 2014.

[9] J.Pons-Llinares, M.Riera-Guasp, J.A. Antonino-Daviu, F. VedreñoSantos, "Transient Diagnosis of Induction Generators via Atom-Based Time-Frequency Transforms", in Proc. Int. Conf. Electrical Machines (ICEM'2014), Berlin, Germany, Sept.2-5, 2014. pp. 1787 - 1793

[10] J.Antonino-Daviu, S.Aviyente, E. G. Strangas, M. Riera-Guasp, J.Roger-Folch ,Rafael B. Pérez, "An EMD-based invariant feature extraction algorithm for rotor bar condition monitoring", in Proc. IEEE Int. Symp. Diagnostics for Electric Machines, Power Electronics \& Drives (SDEMPED’2011), Bologna, Italy, Sept.5-8, 2011, pp.679675 .

[11] F, Vedreño-Santos, M.Riera-Guasp, H,Henao, M.Pineda-Sánchez, and R,Puche-Panadero, "Diagnosis of Rotor and Stator Asymmetries in Wound-Rotor Induction Machines Under Nonstationary Operation Through the Instantaneous Frequency", IEEE Trans. Ind. Electron., vol. 61, no. 9, pp.4247-4259, Sep. 2014.

[12] Y. Gritli, L. Zarri, C. Rossi, F. Filippetti, G.-A. Capolino, and D. Casadei, "Advanced diagnosis of electrical faults in wound rotor induction machines," IEEE Trans. Ind. Electron., vol. 60, no. 9, pp. 4012-4024, Sep. 2013

[13] T. Boukra, A. Lebaroud, and G. Clerc, "Statistical and neural-network approaches for the classification of induction machine faults using the ambiguity plane representation," IEEE Trans. Ind. Electron., vol. 60, no. 9, pp. 4034-4042, Sept. 2013.

[14] P. Gardel, D. Morinigo-Sotelo, O. Duque-Perez, M. Perez-Alonso, and L.A. Garcia-Escudero, "Neural network broken bar detection using time domain and current spectrum data," in Proc. Int. Conf. Electrical 
Machines (ICEM’2012), Marseille, France, Sept. 2-5, 2012, pp. 2490 2495.

[15] S. Hamdani, H. Mezerreg, B. Boutikar, N. Lahcene, O. Touhami, and R. Ibtiouen, "Rotor Fault Diagnosis in a Squirrel-Cage Induction Machine Using Support Vector," in Proc. Int. Conf. Electrical Machines (ICEM'2012), Marseille, France, Sept. 2-5, 2012, pp. 1815 1820.

[16] A. Soualhi, G. Clerc, and H. Razik "Detection and Diagnosis of Faults in Induction Motor Using an Improved Artificial Ant Clustering Technique," IEEE Trans. Ind. Electron., vol. 60, no. 9, pp. 40534062, Sept. 2013.

[17] P. Karvelis, G. Georgoulas, C.D. Stylios, I.P. Tsoumas, J. AntoninoDaviu, and V.Climente-Alarcón, "An Intelligent Icons Approach for Rotor Bar Fault Detections," in Proc. IEEE Annu. Conf. Ind. Electron. (IECON'2013), Vienna, Austria, Nov. 10-13, 2013, pp. 5526-5531.

[18] F. Ferracuti, A. Giantomassi, S. Iarlori, G. Ippoliti, and S. Longhi, "Induction Motor Fault Detection and Diagnosis using KDE and Kullback-Leibler Divergence," in Proc. IEEE Annu. Conf. Ind. Electron. (IECON'2013), Vienna, Austria, Nov. 10-13, 2013, pp. 2923-2928.

[19] R. Romary, R. Pusca, J. P. Lecointe, and J. F. Brudny, "Electrical machines fault diagnosis by stray flux analysis," in Proc. IEEE Workshop Electrical Machines Design, Control and Diagnosis (WEMDCD'2013), Paris, France, Mar. 11-12, 2013, pp. 245-254.

[20] K.N. Gyftakis and J.C. Kappatou, "Evaluation of the Broken Bar Fault Detectability Depending on the Rotor Bar Number," in Proc. IEEE Annu. Conf. Ind. Electron. (IECON'2013), Vienna, Austria, Nov. 10 13, 2013, pp. 2798-2803.

[21] C. Concari, G. Franceschini, C. Tassoni, and A. Toscani, "Validation of a Faulted Rotor Induction Machine Model With an Insightful Geometrical Interpretation of Physical Quantities," IEEE Trans. Ind. Electron., vol. 60, no. 9, pp. 4074-4083, Sept. 2013.

[22] V. Climente-Alarcon, J.A. Antonino-Daviu, E. Strangas, M. RieraGuasp, "Bar Breakage Mechanism and Prognosis in an Induction Motor," in Proc. IEEE Int. Symp. Diagnostics for Electrical Machines, Power Electronics and Drives (SDEMPED'2013), Valencia, Spain Aug. 27-30, 2013, pp. 592-599.

[23] G.M. Joksimovic, J. Riger, T.M. Wolbank, N. Peric, and M. Vašak, "Stator-Current Spectrum Signature of Healthy Cage Rotor Induction Machines," IEEE Trans. Ind. Electron., vol. 60, no. 9, pp. 4025-4033, Sept. 2013.

[24] R. Fiser, K. Drobnic, H. Lavric, M. Nemec, V. Ambrozic, and D. Makuc, " Induction motor parameters in case of rotor electrical asymmetry," in Proc. IEEE Workshop Electrical Machines Design, Control and Diagnosis (WEMDCD'2013), Paris, France, Mar. 11-12, 2013, pp. 271-278.

[25] D.V. Spyropoulos, K.N. Gyftakis, J. Kappatou, E.D. Mitronikas, "The Influence of the Broken Bar Fault on the Magnetic Field and Electromagnetic Torque in 3-phase Induction Motors," in Proc. Int Conf. Electrical Machines (ICEM'2012), Marseille, France, Sept. 2-5, 2012, pp. 1866-1872.

[26] J. Martinez, A. Belahcen, and A. Arkkio, "Combined FE and Two Dimensional Spectral Analysis of Broken Cage Faults in Induction Motors," in Proc. IEEE Annu. Conf. Ind. Electron. (IECON'2013), Vienna, Austria, Nov. 10-13, 2013, pp. 2674-2679.

[27] N. Lahoud, J. Faucher, D. Malec, and P. Maussion, "Electrical Aging of the Insulation of Low-Voltage Machines: Model Definition and Test With the Design of Experiments", IEEE Trans. Ind. Electron., vol. 60 , no. 9, pp.4147-4155, Sep. 2013 .

[28] A. Gandhi, T. Corrigan, and L. Parsa, "Recent Advances in Modeling and Online Detection of Stator Interturn Faults in Electrical Motors", IEEE Trans. Ind. Electron., vol. 58, no. 5, pp.1567-1575, May 2011.

[29] M.F. Cabanas, J.G. Norniella, M.G. Melero, C. H. Rojas, J.M. Cano, F.Pedrayes, G. A. Orcajo, " Detection of Stator Winding Insulation Failures: On-line and Off-line Tests", in Proc. IEEE Workshop Electrical Machines Design, Control and Diagnosis (WEMDCD’2013), Paris, France, March 11-12, 2013, pp. 208-217.

[30] L. Fornasari, A. Caprara, G. C. Montanari, "Partial Discharge measurements in Electrical Machines controlled by Variable Speed Drives: from Design Validation to permanent PD Monitoring", in Proc. IEEE Int. Symp. Diagnostics for Electric Machines, Power Electronics and Drives (SDEMPED'2013), Aug.27-30, 2013, pp.384 390.

[31] A.Picot, D. Malec, P. Maussion, "Improvements on Lifespan Modeling of the Insulation of Low Voltage Machines with Response Surface and Analysis of Variance", in Proc. IEEE Int. Symp. Diagnostics for Electrical Machines, Power Electronics and Drives (SDEMPED'2013), Valencia, Spain, Aug. 27-30, 2013, pp.77-84.

[32] K. Bouzid and G. Champenois,"New Expressions of Symmetrical Components of the Induction Motor Under Stator Faults," IEEE Trans. Ind. Electron., vol. 60, no. 9, pp. 4093-4102, Sep. 2013.
[33] S. Cheng, P. Zhang, and T.G. Habetler, “An Impedance Identification Approach to Sensitive Detection and Location of Stator Turn-to-Turn Faults in a Closed-Loop Multiple-Motor Drive," IEEE Trans. Ind. Electron., Vol. 58, No. 5, pp. 1545-1554, May 2011.

[34] S. Bakhri, N. Ertugrul, and W.L. Soong, "Negative Sequence Current Compensation for Stator Shorted Tum Detection in Induction Motors", in Proc. IEEE Annu. Conf. Ind. Electron. (IECON'2012), Montréal, Canada, Oct.25-28, 2012, pp. 1921-1926.

[35] R. Pusca,C. Demian, D. Mercier, E. Lefevre, and R. Romary, "An improvement of a diagnosis procedure for AC machines using two external flux sensors based on a fusion process with belief functions" in Proc. IEEE Annu.Conf. Ind. Electron. (IECON'2012), Montréal, Canada, Oct.25-28, 2012, pp.5096-5101.

[36] L. Frosini, A. Borin, L. Girometta, G. Venchi, "A novel approach to detect short circuits in low voltage induction motor by stray flux measurement", in Proc. Int. Conf. Electrical Machines (ICEM'2012), Marseille, France, Sept. 2-5, pp. 1536-1542.

[37] S. Toma, L. Capocchi, G.-A. Capolino, "Wound-Rotor Induction Generator Inter-Turn Short-Circuits Diagnosis Using a New Digital Neural Network", IEEE Trans. Ind. Electron., vol. 60, no. 9, pp.40434052, Sep. 2013

[38] Wolkiewicz M., Kowalski C.T., "On-line Neural Network-based Stator Fault Diagnosis System of the Converter-Fed Induction Motor Drive", in Proc. IEEE Annu. Conf. Ind. Electron. (IECON'2013), Vienna, Austria, Nov. 10-13, 2013, pp. 5561-5566

[39] C. Concari, G. Franceschini, and C. Tassoni, "Toward practical quantification of induction drive mixed eccentricity," IEEE Trans. Ind. Applicat., vol. 47, no. 3, pp. 1232-1239, May/June 2011.

[40] F. Vedreño-Santos, M. Riera-Guasp, H. Henao, M. Pineda-Sanchez, and J. A. Antonino-Daviu, "Diagnosis of eccentricity in induction machines working under fluctuating load conditions, through the instantaneous frequency," in Proc. IEEE Annu. Conf. Ind. Electron. (IECON'2012), Montréal, Canada, Oct. 25-28, 2012, pp. 5108-5113.

[41] S. Nandi, T. C. Ilamparithi, S. B. Lee, and D. Hyun, "Detection of eccentricity faults in induction machines based on nameplate parameters," IEEE Trans. Ind. Electron., vol. 58, no. 5, pp. 16731683, May 2011.

[42] A. Ceban, R. Pusca, and R. Romary, "Study of rotor faults in induction motors using external magnetic field analysis," IEEE Trans. Ind. Electron., vol. 59, no. 5, pp. 2082-2093, May 2012.

[43] K. N. Gyftakis and J. C. Kappatou, "The Zero-Sequence Current Spectrum as an On-Line Static Eccentricity Diagnostic Mean in $\Delta_{-}$ Connected PSH-Induction Motors," in Proc. IEEE Int. Symp. Diagnostics for Electrical Machines, Power Electronics and Drives (SDEMPED'2013), Valencia, Spain, Aug. 27-30, 2013, pp. 302-308.

[44] A. J. Fernández Gómez, A. Dziechciarz, and T. J. Sobczyk, "Mathematical Modeling of Eccentricities in Induction Machines by the Mono-harmonic Model," in Proc. IEEE Int. Symp. Diagnostics for Electrical Machines, Power Electronics and Drives (SDEMPED'2013), Valencia, Spain, Aug. 27-30, 2013, pp. 317-322.

[45] F. Immovilli, C. Bianchini, M. Cocconcelli, A.Bellini, and R. Rubini "Bearing Fault Model for Induction Motor With Externally Induced Vibration," IEEE Trans. Ind. Electron., vol. 60, no. 8, pp. 3408-3418, Aug. 2013.

[46] H. Tischmacher and S. Gattermann, "Investigations on Bearing Currents in Converter-Fed Electrical Motors," in Proc. Int. Conf. Electrical Machines (ICEM'2012), Marseille, France, Sept. 2-5, 2012, pp. 1762-1768.

[47] M. Kriese, E. Wittek, S. Gattermann, H. Tischmacher, G. Poll, and B. Ponick, "Influence of Bearing Currents on the Bearing Lifetime for Converter Driven Machines," in Proc. Int. Conf. Electrical Machines (ICEM'2012), Marseille, France, Sept. 2-5, 2012, pp. 1733-1737.

[48] H.L. Schmitt, L.R.B. Silva, P.R. Scalassara, and A. Goedtel, "Bearing fault detection using relative entropy of wavelet components and artificial neural networks," in Proc. IEEE Int. Symp. Diagnostics for Electrical Machines, Power Electronics and Drives (SDEMPED'2013), Valencia, Spain, Aug. 27-30, 2013, pp. 538-543.

[49] C. Harlişca, L. Szabó, L. Frosini, and A. Albini , "Bearing Faults Detection in Induction Machines Based on Statistical Processing of the Stray Fluxes Measurements," in Proc. IEEE Int. Symp. Diagnostics for Electrical Machines, Power Electronics and Drives (SDEMPED'2013), Valencia, Spain, Aug. 27-30, 2013, pp. 371-376.

[50] M. Delgado, G. Cirrincione, A. Garcia, J. A. Ortega, and H. Henao, "Bearing fault detection by a novel condition-monitoring scheme based on statistical-time features and neural networks," IEEE Trans. Ind. Electron., vol. 60, no. 8, pp. 3398-3407, Aug. 2013.

[51] L. Batista, B. Badri, R. Sabourin, and M. Thomas, "Detecting Bearing Defects under High Noise Levels: A Classifier Fusion Approach," in Proc. IEEE Annu. Conf. Ind. Electron. (IECON'2012), Montreal, Canada, Oct. 25-28, 2012, pp. 3880-3886. 
[52] J. Harmouche, C. Delpha, and D. Diallo, "Global Approach for the Classification of Bearing Faults Conditions Using Spectral Features,' in Proc. IEEE Annu. Conf. Ind. Electron. (IECON'2013), Vienna Austria, Nov. 10-13, 2013, pp. 7352-7357.

[53] D. He, L. Ruoyu, and Z. Junda, “ Plastic Bearing Fault Diagnosis Based on a Two-Step Data Mining Approach ," IEEE Trans. Ind. Electron., vol. 60, no. 8, pp. 3429-3440, Aug. 2013.

[54] E. G. Strangas, "Response of electrical drives to gear and bearing faults-Diagnosis under transient and steady state conditions," in Proc. IEEE Workshop Electrical Machines Design, Control and Diagnosis (WEMDCD'2013), Paris, France, March 11-12, 2013, pp. 287-294.

[55] A. Soualhi, G. Clerc, H. Razik, and F. Rivas, "Long-Term Prediction of Bearing Condition by the Neo-Fuzzy Neuron," in Proc. IEEE Int Symp. Diagnostics for Electrical Machines, Power Electronics and Drives (SDEMPED'2013), Valencia, Spain, Aug. 27-30, 2013, pp. 586-591.

[56] B. Zhang, C. Sconyers, C. Byington, R. Patrick, M. Orchard, and G. Vachtsevanos, "A Probabilistic Fault Detection Approach: Application to Bearing Fault Detection," IEEE Trans. Ind. Electron., vol. 58, no. 5, pp. 2011-2018, May 2011.

[57] S. H. Kia, H. Henao, and G.-A. Capolino, "A comparative study of acoustic, vibration and stator current signatures for gear tooth fault diagnosis," in Proc. Int. Conf. Electrical Machines (ICEM'2012), Marseille, France, Sept. 2-5, 2012, pp. 1512-1517.

[58] S.H. Kia, H. Henao, G.-A. Capolino, "Gear Tooth Surface Damage Fault Detection Using Induction Machine Electrical Signature Analysis," in Proc. IEEE Int. Symp. Diagnostics for Electrical Machines, Power Electronics and Drives (SDEMPED'2013), Valencia, Spain, Aug. 27-30, 2013, pp. 358-364.

[59] S.H. Kia, H. Henao, G.-A. Capolino, "Gear Tooth Surface Damage Fault Profile Identification Using Stator Current Space Vector Instantaneous Frequency," in Proc. IEEE Annu. Conf. Ind. Electron. (IECON'2013), Vienna, Austria, Nov. 10-13, 2013, pp. 5482-5488.

[60] D. Zurita, M. Delgado, J.A.Ortega, L.Romeral, "Intelligent Sensor based on Acoustic Emission Analysis applied to Gear Fault Diagnosis," in Proc. IEEE Int. Symp. Diagnostics for Electrical Machines, Power Electronics and Drives (SDEMPED'2013), Valencia, Spain, Aug. 27-30, 2013, pp. 169-176.

[61] I.X. Bogiatzidis, A.N. Safacas, A.N, and E.D. Mitronikas,“ Plastic Bearing Fault Diagnosis Based on a Two-Step Data Mining Approach," IEEE Trans. Ind. Electron., vol. 60, no. 8, pp. 3441-3453, Aug. 2013.

[62] H. Henao, S.H. Kia, G.-A. Capolino, "Torsional-Vibration Assessment and Gear-Fault Diagnosis in Railway Traction System,' IEEE Trans. Ind. Electron., vol. 58, no. 5, pp. 1707-1717, May 2011.

[63] Z. Daneshi-Far, H. Henao, and G.-A. Capolino, "Planetary Gearbox Effects on Induction Machine in Wind Turbine: Modeling and Analysis," in Proc. Int. Conf. Electrical Machines (ICEM'2012), Marseille, France, Sept. 2-5, 2012, pp. 1788-1794.

[64] L. Zarri, M. Mengoni, Y. Gritli, A. Tani, F. Filippetti, G. Serra, and D. Casadei, "Detection and Localization of Stator Resistance Dissymmetry Based on Multiple Reference Frame Controllers in Multiphase Induction Motor Drives," IEEE Trans. Ind. Electron., vol. 60, no. 8, pp. 3506-3518, Aug. 2013.

[65] L. Zarri, M. Mengoni, A. Tani, Y. Gritli, G. Serra, F. Filippetti, D. Casadei, "Full Detection of High-Resistance Connections in Multiphase Induction Machines," in Proc. IEEE Int. Symp. Diagnostics for Electrical Machines, Power Electronics and Drives (SDEMPED'2013), Valencia, Spain, Aug. 27-30, 2013, pp. 505-511.

[66] M. Delgado Prieto, A.Garcia Espinosa, J.R. Riba Ruiz, J.C.Urresty, J. A.Ortega, "Feature Extraction of Demagnetization Faults in Permanent-Magnet Synchronous Motors Based on Box-Counting Fractal Dimension", IEEE Trans. Ind. Electron., Vol. 58, No. 5, pp.1594-1605, May 2011

[67] D. Casadei, F. Filippetti, C. Rossi, and A. Stefani, "Magnets faults characterization for Permanent Magnet Synchronous Motors," in Proc. IEEE Int. Symp. Diagnostics for Electrical Machines, Power Electronics and Drives (SDEMPED'2009), Cargèse, France, Aug.31 Sept3, 2009, pp. 1-6.

[68] J.Urresty, J.R.Riba, M.Delgado, L.Romeral, "Detection of Demagnetization Faults in Surface-Mounted Permanent Magnet Synchronous Motors by Means of the Zero-Sequence Voltage Component", IEEE Trans. Energy Conv., Vol. 27, No. 1, pp. 42-51 March 2012.

[69] J. Urresty, R.Atashkhooei, J.R-Riba, L.Romeral, S. Royo "Shaft Trajectory Analysis in a Partially Demagnetized Permanent-Magnet Synchronous Motor", IEEE Trans. Ind. Electron., vol. 60, No. 8, pp.3454-3461, August 2013.

[70] A.Sarikhani, O.A. Mohammed," Inter-Turn Fault Detection in PM Synchronous Machines by Physics-Based Back Electromotive Force
Estimation", IEEE Trans. Ind. Electron., Vol. 60, No. 8, pp.34723484, August 2013

[71] B. Aubert, J. Regnier, S.Caux, D. Alejo, "On-line Inter-Turn ShortCircuit detection in Permanent Magnet Synchronous Generators", in Proc. IEEE Int. Symp. Diagnostics for Electrical Machines, Power Electronics and Drives (SDEMPED'2013), Valencia, Spain, Aug. 2730, 2013, pp.329-335

[72] S.Cheng, T.G. Habetler,'Using Only the DC Current Information to Detect Stator Turn Faults in Automotive Claw-Pole Generators", IEEE Trans. Ind. Electron., Vol. 60, No. 8, pp.3462-3471, August 2013.

[73] X.Gong, W. Qiao, "Bearing Fault Diagnosis for Direct-Drive Wind Turbines via Current-Demodulated Signals", IEEE Trans. Ind. Electron., Vol. 60, No. 8, pp.3419-3428, August 2013.

[74] Mohammadpour A., Sadeghi S. , Parsa, L. , "A Generalized FaultTolerant Control Strategy for Five-Phase PM Motor Drives Considering Star, Pentagon, and Pentacle Connections of Stator Windings", IEEE Trans. Ind. Electron., Vol. 61, No. 1, pp.63-75 January 2014

[75] H. Saavedra, J.R. Riba, L. Romeral "Inter-turn Fault Detection in Five-Phase PMSMs. Effects of the Fault Severity", in Proc. IEEE Int. Symp. Diagnostics for Electrical Machines, Power Electronics and Drives (SDEMPED'2013), Valencia, Spain, Aug. 27-30, 2013, pp. 520-526.

[76] S. Yang, A. Bryant, P. Mawby, X. Dawei, L. Ran and P. Tavner, "An industry-based survey of reliability in power electronic converters," IEEE Trans. Ind. Applicat., vol. 47, no. 3, pp. 1441-1451, May/Jun. 2011.

[77] J.M. Anderson, R.W. Cox, and P. O'Connor, "Online Algorithm for Early Stage Fault Detection in IGBT Switches," in Proc. IEEE Int. Symp. Diagnostics for Electrical Machines, Power Electronics and Drives (SDEMPED'2013), Valencia, Spain, Aug. 27-30, 2013,pp.1-8.

[78] M. Shahbazi, E. Jamshidpour, P. Poure, S. Saadate, and M.R. Zolghadri, "Open- and Short-Circuit Switch Fault Diagnosis for Nonisolated DC-DC Converters Using Field Programmable Gate Array," IEEE Trans. Ind. Electron., vol. 60, no. 9, pp. 4136-4146, Sept. 2013.

[79] J. O. Estima, N. M. A. Freire, and A. J. M. Cardoso, "Recent advances in fault diagnosis by Park's vector approach," in Proc. IEEE Workshop Electrical Machines Design, Control and Diagnosis (WEMDCD'2013), Paris, France, Mar. 11-12, 2013, pp. 277-286.

[80] J. O. Estima and A. J. M. Cardoso, "A new algorithm for real-time multiple open-circuit fault diagnosis in voltage-fed PWM motor drives by the reference current errors," IEEE Trans. Ind. Electron., vol. 60 , no. 8 , pp. 3496-3505, Aug. 2013

[81] J. O. Estima and A. J. M. Cardoso, "A new approach for real-time multiple open-circuit fault diagnosis in voltage source inverters," IEEE Trans. Ind. Applicat., vol. 47, no. 6, pp. 2487-2494, Nov./Dec. 2011.

[82] N. M. A. Freire, J. O. Estima, and A. J. M. Cardoso, "Open-circuit fault diagnosis in PMSG drives for wind turbine applications," IEEE Trans. Ind. Electron., vol. 60, no. 9, pp. 3957-3967, Sept. 2013

[83] W. Sleszynski, J. Nieznanski, and A. Cichowski, "Open-transistor fault diagnostics in voltage-source inverters by analyzing the load currents," IEEE Trans. Ind. Electron., vol. 56, no. 11, pp. 4681-4688, Nov. 2009

[84] S.M.A. Cruz, M. Ferreira, A.M.S. Mendes, and A.J.M. Cardoso, "Analysis and Diagnosis of Open-Circuit Faults in Matrix Converters," IEEE Trans. Ind. Electron., vol. 58, no. 5, pp. 16481661, May 2011.

[85] D.U. Campos-Delgado and D. R. Espinoza-Trejo, "An ObserverBased Diagnosis Scheme for Single and Simultaneous Open-Switch Faults in Induction Motor Drives," IEEE Trans. Ind. Electron., vol. 58, no. 2, pp. 671-679, Feb. 2011.

[86] T. Orlowska-Kowalska, P. Sobanski, "Simple Sensorless Diagnosis Method for Open-Switch Faults in SVM-VSI-fed Induction Motor Drive," in Proc. IEEE Annu. Conf. Ind. Electron. (IECON'2013), Vienna, Austria, Nov. 10-13, 2013, pp. 8210-8215.

[87] J.F. Martins, V.F. Pires, C.Lima, and A.J.Pires, "Fault detection and diagnosis of grid-connected power inverters using PCA and current mean value," in Proc. IEEE Annu. Conf. Ind. Electron. (IECON'2012), Montreal, Canada, Oct. 25-28, 2012, pp. 5185-5190.

[88] C. Delpha, H. Chen, and D. Diallo, "SVM based diagnosis of inverter fed induction machine drive a new challenge," in Proc. IEEE Annu. Conf. Ind. Electron. (IECON'2012), Montreal, Canada, Oct. 25-28, 2012, pp. 3931-3936.

[89] X-S. Pu, T. H. Nguyen, D-C. Lee, K-B. Lee, and J-M. Kim, "Fault Diagnosis of DC-Link Capacitors in Three-Phase AC/DC PWM Converters by Online Estimation of Equivalent Series Resistance," IEEE Trans. Ind. Electron., vol. 60, no. 9, pp. 4118-4127, Sept. 2013. 
[90] H.A. Sher, K.E Addoweesh, Y. Khan, and S.A.R. Kashif, "Performance of Inverter Fed Induction Motor under Open Circuit DC link Capacitor," in Proc. IEEE Annu. Conf. Ind. Electron. (IECON'2012), Montreal, Canada, Oct. 25-28, 2012, pp. 651-655.

[91] A. Izadian and P. Khayyer, "Application of Kalman filters in modelbased fault diagnosis of a DC-DC boost converter," in Proc. IEEE Annu. Conf. Ind. Electron. (IECON'2010), Glendale, USA, Nov. 710, 2010, pp. 369-372.

[92] Y. Chen, X. Pei, S. Nie, and Y. Kang, "An Observer-Based Diagnosis Scheme for Single and Simultaneous Open-Switch Faults in Induction Motor Drives," IEEE Trans. Ind. Electron., vol. 58, no. 5, pp. 1634 1647, May 2011.

[93] B. Ji, V. Pickert, W.P. Cao, and L. Xing, "Onboard condition monitoring of solder fatigue in IGBT power modules," in Proc. IEEE Int. Symp. Diagnostics for Electrical Machines, Power Electronics and Drives (SDEMPED'2013), Valencia, Spain, Aug. 27-30, 2013, pp. 9-15.

[94] I. Vaalasranta, J. Pippola, and L. Frisk, "Power MOSFET failure and degradation mechanisms in flyback topology under high temperature and high humidity conditions," in Proc. IEEE Int. Symp. Diagnostics for Electrical Machines, Power Electronics and Drives (SDEMPED'2013), Valencia, Spain, Aug. 27-30, 2013, pp. 16-22.

[95] B. R. O. Baptista, M.B. Abadi, A.M. S. Mendes, S. M. A. Cruz, "The Performance of a Three-Phase Induction Motor fed by a Three-Level NPC Converter with Fault Tolerant Control Strategies," in Proc. IEEE Int. Symp. Diagnostics for Electrical Machines, Power Electronics and Drives (SDEMPED'2013), Valencia, Spain, Aug. 27-30, 2013, pp. 497-504.

[96] T.T.L.Pham, F. Richardeau, and G. Gateau, "Real-Time Monitoring for a Five-Level Double-Boost Power Factor Controller Including Postfault Reconfiguration," IEEE Trans. Ind. Electron., vol. 60, no. 9, pp. 4128-4135, Sept. 2013.

[97] F. Carnielutti and H. Pinheiro, "New Modulation Strategy for Asymmetrical Cascaded Multilevel Converters Under Fault Conditions," in Proc. IEEE Annu. Conf. Ind. Electron. (IECON'2013), Vienna, Austria, Nov. 10-13, 2013, pp. 1074-1079.

[98] S. Khwan-on, L.de Lillo, L. Empringham, and P. Wheeler, "FaultTolerant Matrix Converter Motor Drives With Fault Detection of Open Switch Faults," IEEE Trans. Ind. Electron., vol. 59, no. 1, pp. 257-268, Jan. 2012.

[99] Y. Song, and B. Wang, "Survey on Reliability of Power Electronic Systems," IEEE Trans. on Power Electronics vol. 28, no.1, pp. 591604, Jan. 2013.

\section{BIOGRAPHIES}

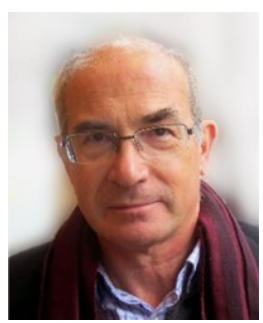

Martin Riera-Guasp (M'94-SM'12) received the M.Sc. degree in industrial engineering and the Ph.D. degree in electrical engineering from the Universitat Politècnica de València, Valencia, Spain, in 1981 and 1987, respectively.

Currently, he is an Associate Professor with the Department of Electrical Engineering, Polytechnic University of Valencia. His research interests include condition monitoring of electrical machines, applications of signal analysis techniques to electrical engineering, and efficiency in electric power applications.

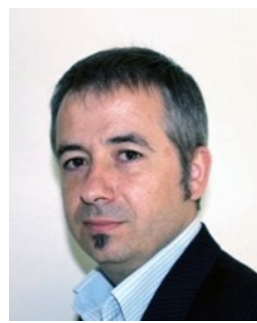

Jose A. Antonino-Daviu (M'06-SM'12) received the M.Sc. and Ph.D. degrees in electrical engineering from the Universitat Politècnica de València, Valencia, Spain, in 2000 and 2006, respectively. He worked in the private sector, being involved in several international projects. Currently, he is an Associate Professor with the School of Industrial Engineering, Universitat Politècnica de València. His primary research interests include conditionmonitoring of electric machines, wavelet theory and its application to fault diagnosis, and design and optimization of electrical installations and systems.

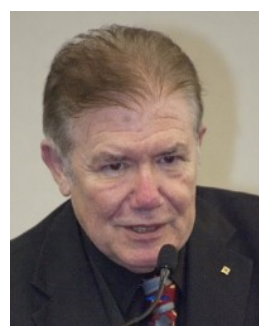

Gérard-André Capolino (A'77-M'82-SM'89F'02) was born in Marseille, France. He received the B.Sc. degree in electrical engineering from Ecole Centrale de Marseille, France, in 1974, the M.Sc. degree from Ecole Supérieure d'Electricité, Paris, France, in 1975, the Ph.D. degree from the Aix-Marseille University, Marseille, France, in 1978, and the D.Sc. degree from Institut Polytechnique de Grenoble, France, in 1987.

In 1994, he joined the University of Picardie "Jules Verne," Amiens, France where he is now a Chair Professor of Electrical Engineering.

Dr. Capolino is an Associate Editor of IEEE TRANSACTIONS ON POWER ELECTRONICS, IEEE TRANSACTIONS ON INDUSTRIAL ELECTRONICS and IEEE ACCESS. He is also the acting Chair for the Steering Committee of the International Conference on Electrical Machines (ICEM). He was a recipient of the 2008 IEEE-IES Dr.-Ing. Eugene Mittelmann Achievement Award, the 2010 ICEM Arthur Ellison Achievement Award, and the 2011 IEEE-PELS Diagnostics Achievement Award. 